\title{
Understanding the Radiation Resistance Mechanisms of Nanocrystalline Metals from Atomistic Simulation
}

\author{
Liang Zhang ${ }^{1,2}$ (D)
}

Citation: Zhang, L. Understanding the Radiation Resistance Mechanisms of Nanocrystalline Metals from Atomistic Simulation. Metals 2021, 11, 1875. https://doi.org/10.3390/ met11111875

Academic Editor: Jaimyun Jung

Received: 25 October 2021

Accepted: 19 November 2021

Published: 22 November 2021

Publisher's Note: MDPI stays neutral with regard to jurisdictional claims in published maps and institutional affiliations.

Copyright: (C) 2021 by the author. Licensee MDPI, Basel, Switzerland. This article is an open access article distributed under the terms and conditions of the Creative Commons Attribution (CC BY) license (https:// creativecommons.org/licenses/by/ $4.0 /)$.
1 International Joint Laboratory for Light Alloys (Ministry of Education), College of Materials Science and Engineering, Chongqing University, Chongqing 400044, China; liangz@cqu.edu.cn

2 Shenyang National Laboratory for Materials Science, Chongqing University, Chongqing 400044, China

\begin{abstract}
Metallic materials produce various structural defects in the radiation environment, resulting in serious degradation of material properties. An important way to improve the radiation-resistant ability of materials is to give the microstructure of materials a self-healing ability, to eliminate the structural defects. The research and development of new radiation-resistant materials with excellent self-healing ability, based on defects control, is one of the hot topics in materials science. Compared with conventional coarse-grained materials, nanocrystalline metals with a high density of grain boundary (GB) show a higher ability to resist radiation damage. However, the mechanism of GB's absorption of structural defects under radiation is still unclear, and how to take advantage of the GB properties to improve the radiation resistance of metallic materials remains to be further investigated. In recent decades, atomistic simulation has been widely used to study the radiation responses of different metals and their underlying mechanisms. This paper briefly reviews the progress in studying radiation resistance mechanisms of nanocrystalline metals by employing computational simulation at the atomic scale.
\end{abstract}

Keywords: radiation resistance; self-healing mechanism; molecular dynamics; grain boundary

\section{Introduction}

Radiation-induced defects in materials lead to serious degradation of material properties during radiation that can ultimately cause the material to fail. In the radiation environment, vacancies and interstitial atoms are the primary structural defects when energetic particles collide with materials [1]. These defects may subsequently evolve into microstructural flaws, such as voids, stacking fault tetrahedra (SFT), and dislocation loops, etc. [2-9], leading to macroscopic degradation of the performance of the material [10]. The ability of a material to resist radiation damage is determined by how well the microstructure can remove vacancies, interstitial atoms, and their clusters [3]. Much research has been devoted to understanding and controlling the behavior of structural defects to design materials that can withstand these harsh environments [11-20]. It has long been known that grain boundaries (GBs) can serve as defect sink for absorbing and annihilating radiationinduced point defects and traps for helium [21-24]. Therefore, nanocrystalline materials, which contain a high density of GBs, have demonstrated enhanced radiation tolerance compared to large grain counterparts under certain conditions. For conventional metals, interstitial defects caused by radiation quickly move to the surface and cause swelling, as shown in Figure 1a. Vacancy defects slowly agglomerate, forming immobile voids that impede dislocation motion and cause hardening and embrittlement of the material. In nanocrystalline metals, GBs occupy a high proportion of volume, as shown in Figure 1b. Interstitial atoms can be captured by surrounding GBs, and most vacancies can be removed within the annihilation range of the boundary, leaving a healed crystal, and giving the material good radiation resistance.

The existence of the self-healing ability of nanocrystalline metals means that they can have both excellent mechanical properties and good radiation resistance, which pro- 
vides an opportunity for the development of metallic structure materials with excellent comprehensive properties. However, the detailed mechanisms, at the level of the atomic structure of GBs that enable a nanomaterial to be stable in the radiation environment, are only just beginning to be clarified. The exact process by which this happens is not well understood, making it difficult to design the microstructure of materials to optimize their radiation resistance ability. Radiation damage is not an equilibrium phenomenon, which complicates the execution of experiments and the interpretation of the results, because the time and dose dependence of radiation damage is not straightforward [25]. While experiments can provide some indirect insight into the interaction between collision cascades and boundaries, it is very difficult to capture the evolution of structural defects during collision cascades because of the time scale constraints of the characterization methods. Understanding how GB influences radiation damage production necessitates a capability that has an atomistic resolution on the picosecond timescale. As a complement to experiments, researchers are increasingly turning to computer simulation to uncover the atomic-level processes involved.

Facilitated by rapid increases in computational power, atomistic simulation has been used extensively to study the radiation resistance behavior of nanocrystalline materials and great progress has been made in simulating and understanding self-healing mechanisms at an atomic scale. In particular, molecular dynamics (MD) simulation has been widely used to understand the GB structure and its associated radiation resistance mechanisms because of its advantage at the femtosecond time scale. For example, the large-scale atomic/molecular massively parallel simulator (LAMMPS) is a classical MD software package developed by the Sandia National Laboratory [26], which is the most extensively used simulator for studying the properties of metallic materials. Also, recent post-processing technologies such, as visualization tools (AtomEye, OVITO, etc.) $[27,28]$ and structure identification methods (dislocation analysis, Wigner-Seitz defect analysis, etc.) [29,30] provide more information on the atomic scale.

(a)

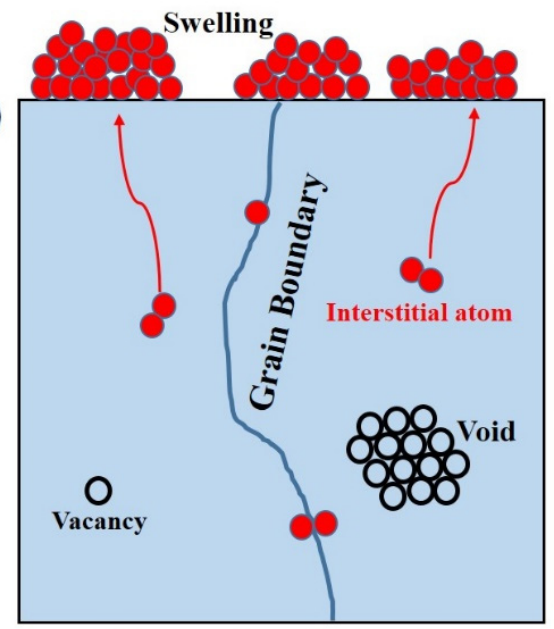

Conventional Metal (b)

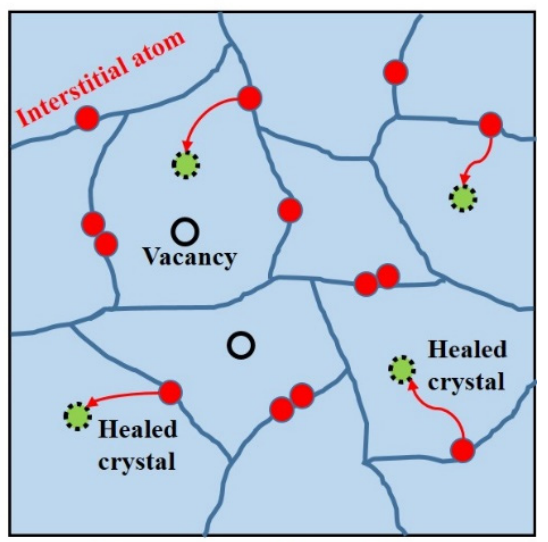

Nanocrystalline Metal

Figure 1. Schematic of the evolution of self-interstitial atoms (SIAs) and vacancies caused by radiation in (a) conventional material and (b) nanomaterial.

This article presents a brief overview of the recent studies in understanding the radiation resistance mechanism of nanocrystalline metals by atomistic simulations. In Section 2, the interaction between GBs and different types of irradiated defects is reviewed. Simulations of collision cascades near GBs reveal that GBs interact strongly with the cascade, exhibiting a biased absorption capacity for the point defects. GB structure and the absorbed defect content at GBs play a significant role in absorbing defects. While Section 2 focuses on stationary GBs, Section 3 focuses on the interaction between moving GBs and 
radiation-induced structural defects, revealing that GB migration is an important selfhealing mechanism of materials under radiation. Moreover, some recent experimental studies have reported that nanotwinned metals can exhibit unprecedented radiation tolerance, which renewed the conventional understanding of nanotwinned materials on the alleviation of radiation damage. To illustrate this phenomenon, Section 4 presents atomistic simulations of the interaction between twin boundary and the radiation-induced structural defects. The simulation results provide useful information into how GBs influence radiation damage evolution, providing atomistic insights and the foundation for designing radiation-tolerant nanomaterials.

\section{Influence of GBs on Collision Cascade}

A collision cascade (also known as a displacement cascade) is a set of nearby adjacent energetic collisions of atoms induced by an energetic particle in a material. If the maximum atom or ion energies in a collision cascade are higher than the threshold displacement energy of the material (tens of eVs or more), the collisions can permanently displace atoms from their lattice sites and produce defects. Radiation damage is measured in "displacements per atom" (dpa) - that is, how often each atom is blasted away from its crystal site. A fusion reactor will produce many hundreds of dpas over its lifetime, which means that each atom in its structure will be removed hundreds of times [4]. Radiationresistant materials must be capable of self-healing this extent of damage.

In the past 20 years or so, studies on the simulation of irradiated structural defects near material interfaces have shown that GBs have a significant effect on the structural defects caused by collision cascade [31-46]. Sugio et al. [47] conducted the first MD simulation of collision cascades near GBs. They simulated collision cascades with the primary knock-on atom (PKA) energies between 1 and $5 \mathrm{keV}$, near a $\Sigma 5$ twist GB in Ag, and found that GB interacted strongly with the cascade, preferentially absorbing interstitials over vacancies, resulting in a vacancy-rich damage state in the grain interior. The biased absorption of interstitials has since been confirmed by many other studies and was thought to be a general result (see Ref. [48] and references therein). Samaras and coworkers [31,34] performed collision cascades with different initial energies in various places within the microstructure in a polycrystalline $\mathrm{Ni}$ and Fe. They also reported that GBs preferentially absorbed interstitials, leaving a defective structure that primarily consisted of vacancies in grain. The interstitials or interstitial clusters preferentially migrate to the regions of tensile pressure at GB and annihilate excess free volume of GB. In particular, due to the large number of vacancies formed near the GB, they readily form larger vacancy clusters. In bcc Fe, these clusters are void-like vacancy clusters, while in fcc $\mathrm{Ni}$, they are mainly stacking fault tetrahedra (SFTs), due to the lower stacking fault energies in fcc metals. In the simulations of Fe, vacancy clusters containing 35 vacancies were observed, in contrast to the largest clusters observed in single crystals that contained only 5 vacancies [34]. This result proves again that the preferential absorption of interstitial atoms over vacancies by GBs results in more vacancies in the bulk region.

The interaction between GBs and collision cascade-induced structural defects has been investigated using atomistic simulations for different GBs and materials, offering significant insight into how these interactions depend on GB structure. Bai et al. [36] studied the effect of GB structure on the interaction between GB and structural defects in $\mathrm{Cu}$ during radiation. They simulated collision cascades near a number of GBs, including tilt and twist boundaries and symmetric and asymmetric boundaries. It was found that the ability of GB to absorb interstitials was strongly related to the structure of the boundary. Among the investigated GBs in their study, the $\Sigma 5$ twist GB absorbed the most interstitial atoms, inducing the formation of SFTs nearby in some cases. The inherent flexibility of the structure of the twist allows it to absorb more interstitials than other boundaries. In addition, they found GBs that have greater thermodynamic interactions with defects lead to the smallest vacancy production, which is the case of the asymmetric $\Sigma 11$ and $\Sigma 45$ GBs, as shown in Figure 2. Smith et al. [38-40] studied Fe by MD simulations and they observed 
that boundaries acted as barriers to collision cascades, disrupting focused collision from crossing the boundary plane. In particular, the total number of defects produced in collision cascades near the twist boundary was four times greater than near the tilt boundary, which is consistent with the result in the study of Bai et al. [36]. In the case of the tilt boundary, the defects preferentially accumulated in the "kite" of the structure (a structural unit of geometric morphology of this GB) because of the larger free volume in the middle of the structural unit than in the bulk. The above simulation results indicate that the defect absorption is sensitive to the specific structural features of the GBs. Tschopp et al. [49] used molecular statics and MD simulations to investigate GB sink strength of $\alpha$-Fe at the nanoscale. The results show that both low- and high-angle GBs are effective sinks for point defects, with a few low- $\Sigma$ GBs (e.g., the $\Sigma 3\{112\}$ twin boundary) that have properties different from the rest. The majority of GB sites have larger binding energy for interstitials than vacancies. Therefore, there is an energetic driving force for interstitial atoms to occupy most GB sites over vacancies, and interstitials have about three times greater site strength than vacancies. Additionally, they explored the effect of GB energy, disorientation angle, and $\Sigma$ designation on the boundary sink strength, and found the strongest correlation occurred between the GB energy and the mean point defect formation energies.
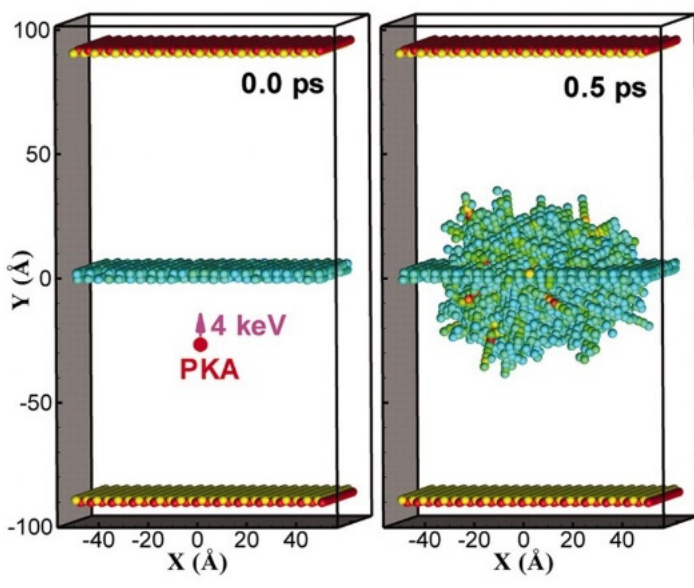

(a)

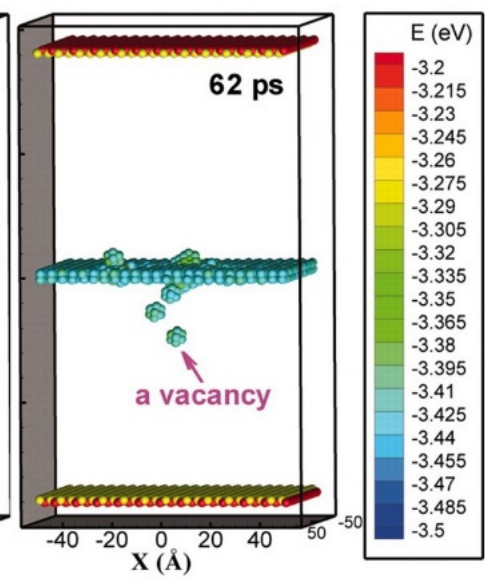

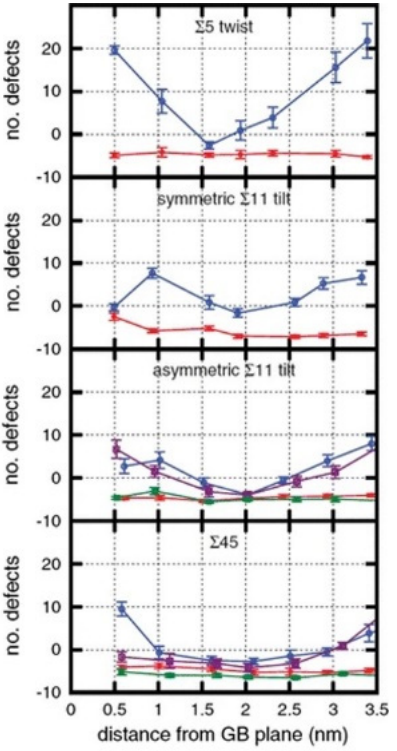

(b)

Figure 2. (a) Snapshots of an MD simulation of a collision cascade near a $\Sigma 11\{131\}$ symmetric tilt GB at $300 \mathrm{~K}$. The atoms are colored by their potential energy. The atoms are colored by their potential energy. Atoms with energies less than $3.43 \mathrm{eV}$ are removed to highlight the structural defects. (b) The number of interstitials and vacancies surviving in the bulk region near four types of GBs after $4 \mathrm{keV}$ collision cascades at $300 \mathrm{~K}$. The numbers are relative to the number of Frenkel pairs produced in equivalent cascades in single crystals. The symbol colors represent the following: blue-vacancy numbers for PKAs initiated in the lower grain; red-interstitial numbers for PKAs initiated in the lower grain; purple-vacancy numbers for PKAs initiated in the upper grain; green-interstitial numbers for PKAs initiated in the upper grain. Reproduced with permission from Refs. [4,36]. Copyright 2021 American Physical Socity.

Simulations revealed that the sink ability of GBs for interacting with point defects is not only influenced by the intrinsic property of GB but also depends on the radiation conditions through the absorbed defect content at the boundary. That is, the damaged (irradiated) boundaries interact with defects in a different way than the pristine (unirradiated) boundaries. With the change of defect content at GB, the interaction between GB and nearby defects and the annihilation rate of defects also changes, thus affecting the sink efficiency. In particular, the thermodynamic interaction of defects with damaged boundaries tends to be both longer ranged and energetically much stronger than that with pristine boundaries. 
For example, by performing a temperature-accelerated MD simulation, Bai et al. [4] showed that GBs firstly capture the radiation-induced interstitial atoms after collision cascades, leaving the abundant vacancies in grain. Then, the excess interstitial atoms on GBs escape back to grains and combine with nearby vacancies, thus promoting the vacancy-interstitial recombination. The "absorption-emission-recombination" process is illustrated in Figure 3. There is a much lower energy barrier of the interstitial-vacancy recombination mechanism than that for vacancy migration, which improves the recovery compared with that of vacancy migration to the boundary [25]. The recombination mechanism gives atomic-scale evidence to reveal the good radiation resistance of nanocrystalline metals.

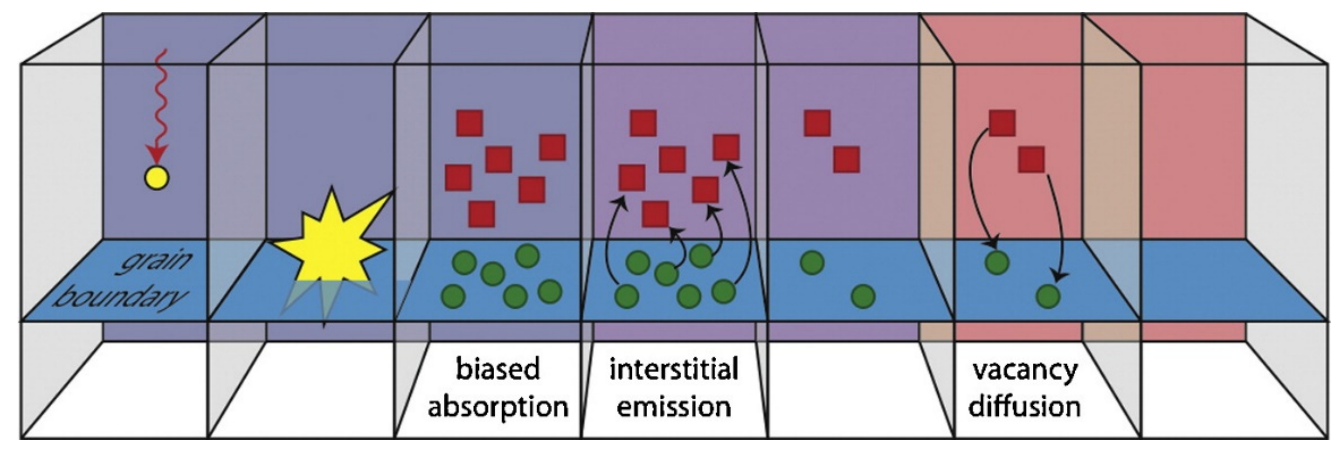

Figure 3. Schematic of the absorption-emission-recombination process during the interaction between GB and the point defects, caused by collision cascades. Reproduced with permission from Ref. [25]. Copyright 2021 Clearance Center.

\section{Dynamic Interaction between GBs and Structural Defects}

Previous studies have shown that GB can provide a large energetic driving force for interstitial atoms to segregate to GB, while the mobility of radiation-induced vacancies and their clusters (such as voids and SFTs) is generally lower than that of the interstitial atoms [4,49-51]. In some radiation experiments, the vacancy defects become nearly immobile under a low-temperature condition [52-54], but the annihilation of vacancies is still somehow enhanced by GBs in these experiments, indicating alternative mechanisms (instead of the conventional vacancy diffusion mechanism) that can assist the annihilation of vacancy defects within grain interiors. The understanding of how defects interact with GB at the atomic scale is still progressing [48,55-57]. Atomistic simulations offer an opportunity to study the radiation resistance mechanisms at the atomic scale, as the interstitial-vacancy recombination mechanism described in the last section. However, it is noticed that when experiments or models are used to understand the effect of GBs on displacement damage caused by point defects, boundaries are typically either assumed to be generic in form or static objects with fixed properties during radiation [58]. The actual situation is that various structural defects frequently move under the action of temperature and local stress. For example, vacancies, interstitials, and theirs clusters exhibit a random walk via thermal diffusion mechanism [24,52,59]. Also, nanocrystalline metals with ultrafine grains are very unstable, due to recrystallization and grain growth caused by the migration of GBs [60-65].

Jin et al. [66] present MD simulations of prolonged radiation damage evolution in $\mathrm{Cu}$ bicrystals with increasing radiation dose. The SFTs formed by radiation damage cascades show preferential migration to the irradiated GBs. Interstitial-loaded GBs are observed to be dynamically resilient and persistently interact with the SFT, revealing a self-healing response to radiation damage. Figure 4a shows radiation-induced defect clusters and GB evolution in $\Sigma 5(210) \mathrm{Cu}$ at different doses. At a low radiation dose of 0.001 dpa (two collision cascades at $5 \mathrm{keV}$ ), point defects and interstitial-loaded GB were produced. A number of radiation-induced SFTs were formed between GBs at $0.079 \mathrm{dpa}$. At higher doses of $0.22 \mathrm{dpa}$, the SFTs do not appear to grow in size and number because they are observed to interact with GBs where they annihilate. Figure $4 \mathrm{~b}$ shows the SFT annihilation process via interaction with $\Sigma 5(210)$ GB. A radiation-induced SFT migrates to the boundary, then 
GB becomes locally distorted upon contact. Finally, the SFT is absorbed, returning the distorted GB to a straight profile. The results also show the size effect of GBs on defect annihilation and the defect cluster density shows a drastic drop when the grain spacing is smaller than $6 \mathrm{~nm}$. The simulation work presents a perspective on GB-mediated damage reduction in radiation-resistant nanomaterials via the mechanism of dynamic moving of SFTs into GB.

(a)
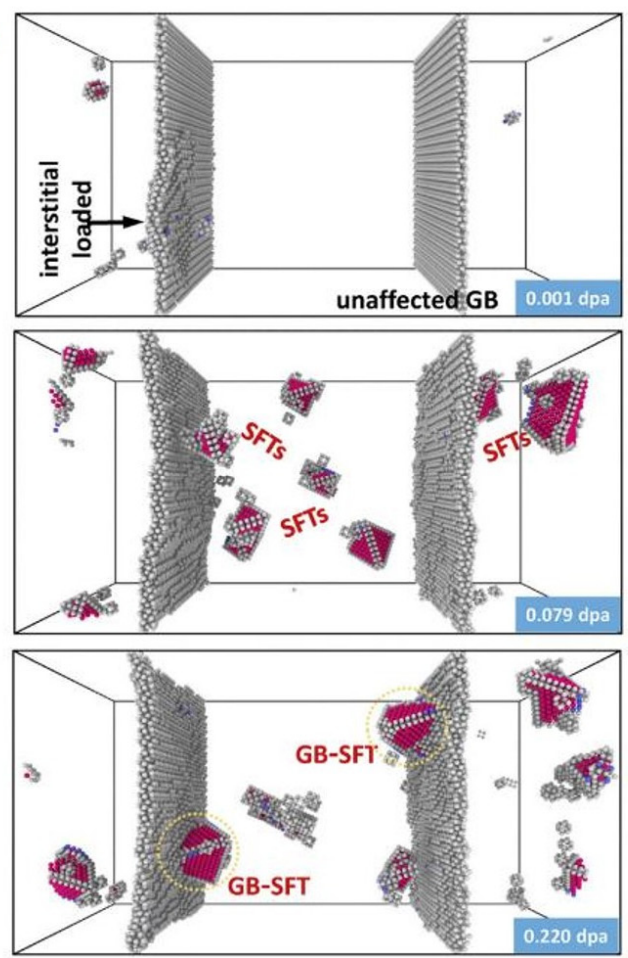

(b)

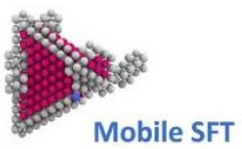

GB

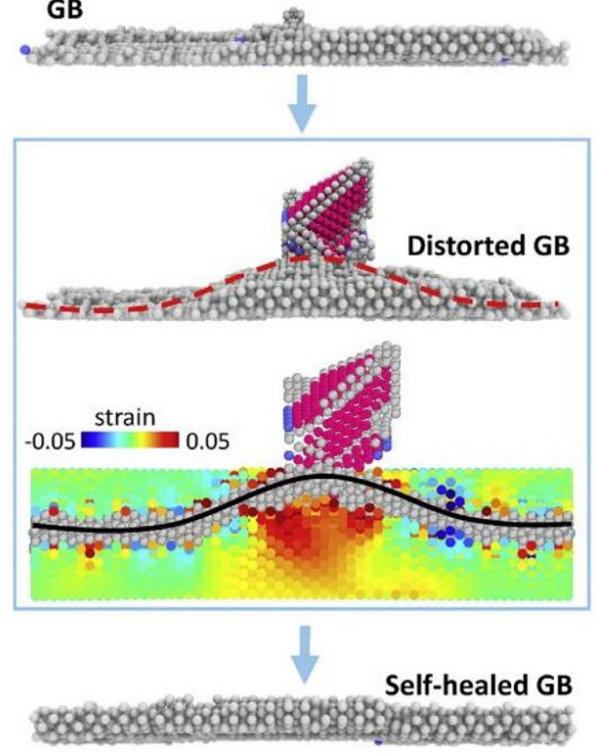

Figure 4. (a) Radiation-induced defect clusters and GB evolution in $\Sigma 5(210) \mathrm{Cu}$ at different doses. (b) SFT annihilation process via interaction with a GB. Atoms are color coded according to their structures (red-hexagonal close-packed (HCP); blue-body-centered cubic (BCC); grey-other structure, face-centered cubic (FCC); atoms not shown). Reproduced with permission from Ref. [66]. Copyright 2021 Clearance Center.

The shear-coupled GB migration has been well determined by experimental observations [62,67-69] and MD simulations [70-72]. In recent computational studies, the dynamic migration of GBs was found to be an important self-healing mechanism of nanocrystalline metals that can effectively remove the radiation-induced structural defects. Zhang et al. [73] examined the interaction between the migrating GB and SFT in bicrystal $\mathrm{Cu}$ using MD simulations. GBs were intentionally selected here to represent both the high-angle GBs and the low-angle GBs, including the $\Sigma 5(310), \Sigma 5(210), \Sigma 37(750)$, and $\Sigma 61(650)$ GBs. The results show that GB can migrate along a direction perpendicular to the boundary plane under shear stress. The efficiency of GB absorbing SFT is sensitive to the structural characteristics of GB. Figure 5 shows the snapshots of interactions between GBs and the preexisting SFT at $10 \mathrm{~K}$. For $\Sigma 5(310)$ GB and $\Sigma 5(210) \mathrm{GB}$, the SFT annihilated gradually into the boundary plane as the GB migration progressed, and it was eventually absorbed by the GB, leaving behind a defect-free area. In the case of $\Sigma 37(750)$ GB, the SFT can also be destructed by the sweeping GB, but the annihilation or absorption of the SFT was incomplete, causing the remaining part of SFT to be broken down into several mono-vacancies or small vacancy clusters. For $\Sigma 61(650)$ GB, when the GB passes through, the configuration of SFT does not change, essentially. The simulation results obtained at the extremely low temperature indicate that the GB structure can play a significant role in the removal of SFT. That is, the high-angle GBs show a strong ability to annihilate the SFT, while the sink efficiency for 
absorbing SFT of the low-angle GBs is relatively weak or even is not evidenced. However, the increase of temperature can facilitate the collapse of SFT at the low-angle GB [73].
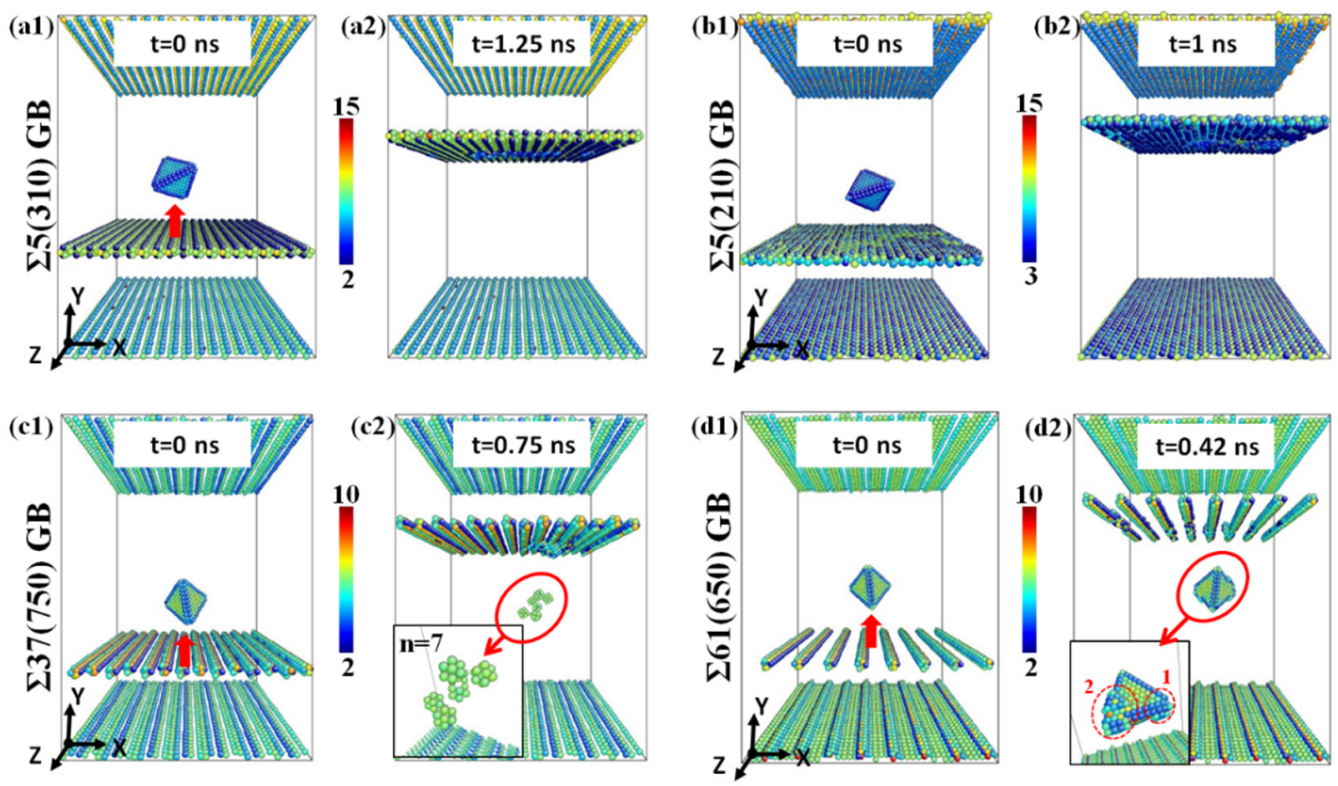

Figure 5. Snapshots of the atomic images before and after the interaction between SFT and different GBs at 10 K. (a1,a2) $\Sigma 5(310)$ GB; (b1,b2) $\Sigma 5(210)$ GB; (c1,c2) $\Sigma 37(750)$ GB; and (d1,d2) $\Sigma 61(650)$ GB. The atoms are colored according to centrosymmetry value, FCC atoms not shown. Reproduced with permission from Ref. [73]. Copyright 2021 Clearance Center.

Zhang et al. [74] further studied the interaction between dynamic moving GBs and nano-voids. The simulation results show that the migrating GB can be pinned to voids, freely traversed voids, or dissolved voids in the process of their interaction. At low temperatures, the voids show an obvious drag effect to GB motion, which is different from the result of the GB-SFT interaction [73]. The retarding pressure applied to the migrating GB by a void was found to be closely related to the surface area of the void, the degree of contact between GB and void, and GB energy. The increase of temperature can effectively reduce the resistance of void to GB movement and promote void absorption by GB. By investigating the thermal stability of a void at the stationary GB, it was found that the dissolution of voids at a moving GB cannot be attributed solely to the thermal diffusion mechanism. The dynamic migration of high-angle GBs can significantly accelerate the dissolution time of the void. Figure 6 illustrates the dissolution mechanism of a void at the migrating $\Sigma 5(310)$ GBs during their interaction. Atomistic analysis indicated that the migrating GB rearranged the atoms on the void surface by the collective motion of structural units, as outlined by the solid lines on GB. The yellow atoms were relocated from the surface of the void into lattice structure after the GB passed, resulting in the shrink of the void. The structural transformation occurred at GB during its interaction with the void, which provides an efficient diffusion channel for transporting the vacancies that absorbing from the void. 

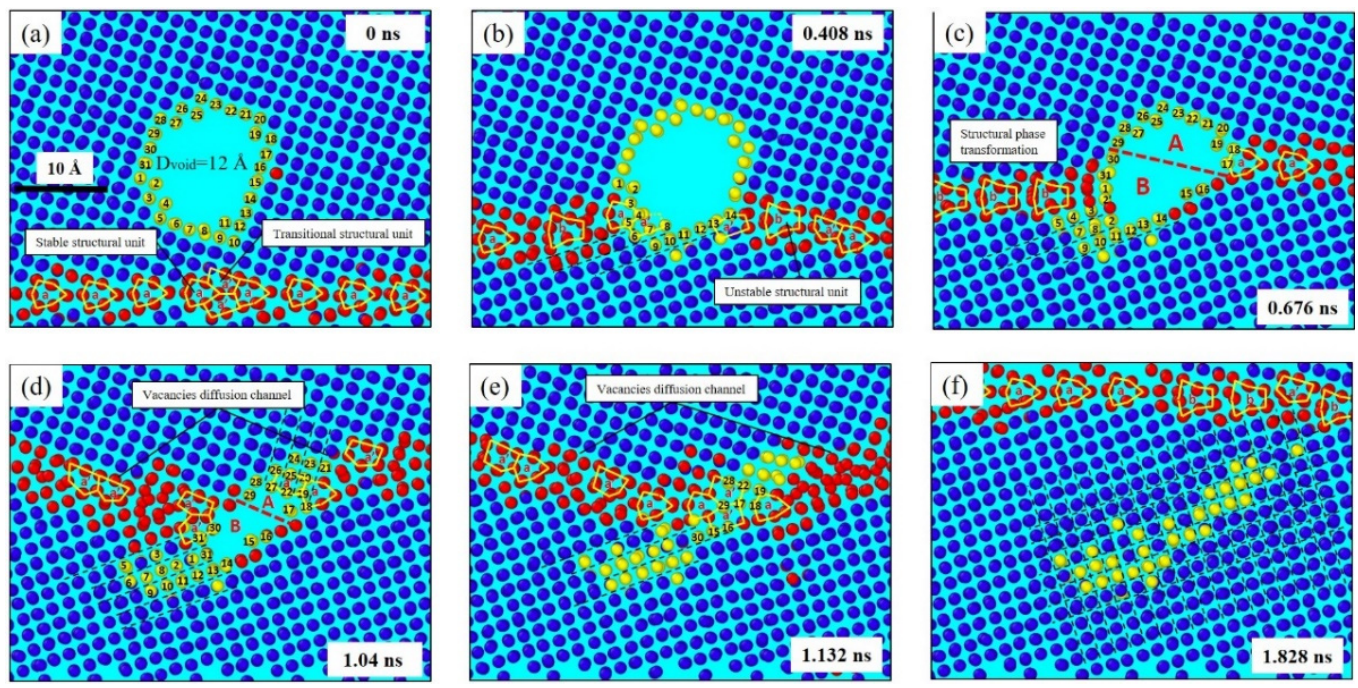

Figure 6. (a-f) Atomic view of interaction between the migrating $\Sigma 5(310) \mathrm{GB}$ and a void at different simulation time. The atoms on the void surface are colored in yellow and the structural units are outlined by the yellow solid lines. Atoms are color coded according to their structures (blue-FCC; red-other structure). Reproduced with permission from Ref. [74]. Copyright 2021 Clearance Center.

\section{Self-Healing Mechanism of Nanotwinned Metals under Radiation}

Nanotwinned metals can exhibit good physical properties (high conductivity and thermal stability) and advanced mechanical properties (high strength and good ductility) [75-77]. However, it has long been accepted that the nanotwinned metals have weak radiation resistance because they contain mostly coherent twin boundaries (CTBs), which are considered ineffective sinks for the radiation-induced crystal defects $[35,36,78]$. Recently, in situ studies have reported that nanotwinned metals (e.g., $\mathrm{Cu}$ and Ag) can also exhibit unprecedented radiation tolerance, and unexpectedly, self-healing of the twin boundaries in response to radiation was observed [79-81]. While these experimental findings renewed the conventional understanding of nanotwinned materials on the alleviation of radiation damage, the underlying atomic mechanisms are not clear yet.

Jiao et al. [82] studied the radiation response of nanotwinned $\mathrm{Cu}$ by MD simulation, and compared the ability of GBs and twin boundaries to absorb irradiated structural defects. The simulations reveal that GBs can serve as excellent sinks for radiation-induced point defects, but coherent twin boundaries (CTBs) are poor sinks. As shown in Figure 7, the structural integrity of CTBs remains intact as radiation-induced defects pass through them and ultimately get absorbed into GBs. The authors concluded that twin boundaries can only enhance the strength and ductility of nanotwinned metals but have a limited role in radiation resistance. Although the key mechanisms associated with twin boundaries observed in this study are consistent with some experimental findings, the simulation results do not explain the experimental phenomenon that twin boundaries lead to reduced point defect density and smaller defect clusters. Wu et al. [83] simulated multiple collision cascades of nanotwinned $\mathrm{Cu}$ with different twin spacings. They analyzed the microstructural evolution in the nanotwinned $\mathrm{Cu}$ during the collision cascades and found that the smaller size of defect clusters and lower defect density is seen in the nanotwinned $\mathrm{Cu}$ with smaller twin spacing. Also, it was found that a number of defect clusters could be removed via their frequent interactions with the coherent twin boundaries during the collision cascades, which induces either the migration of CTBs or the healing of CTBs. 


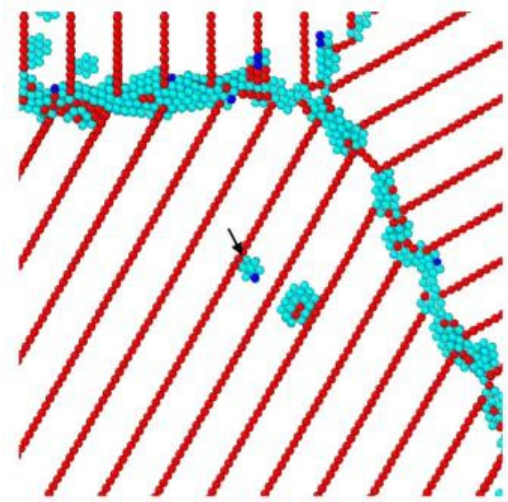

(a) $362 \mathrm{ps}$

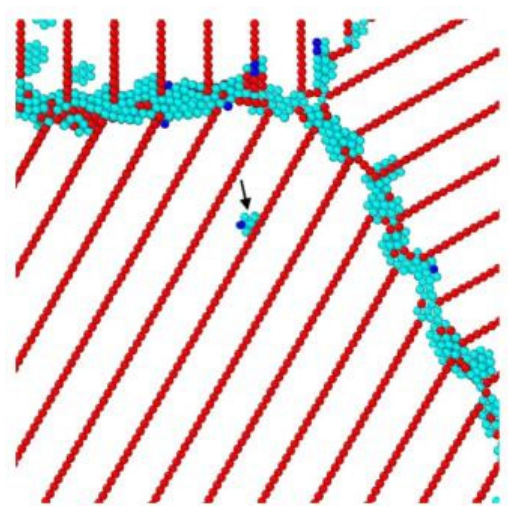

(c) $762 \mathrm{ps}$

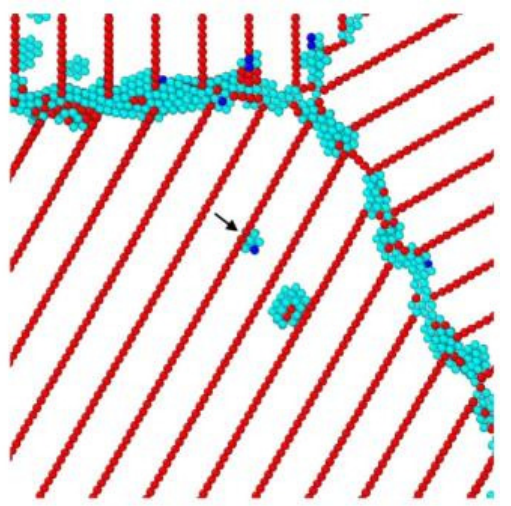

(b) $562 \mathrm{ps}$

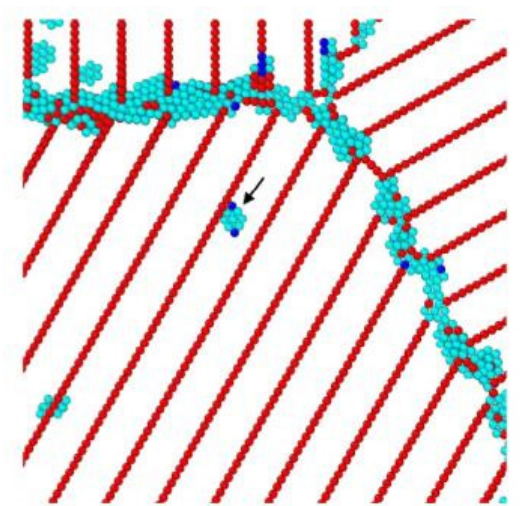

(d) $962 \mathrm{ps}$

Figure 7. (a-d) Atomistic images showing the point defect cluster crossing a CTB at different simulation time during equilibration after radiation cascade. Atoms are color coded according to their structures (blue-BCC; red-HCP; cyan-other structure; FCC atoms not shown). Reproduced with permission from Ref. [82]. Copyright 2021 Clearance Center.

Existing simulation models, typically used in MD simulations, generally assume perfect $\Sigma 3\{111\}$ CTBs to study their mechanical and physical properties [84-86] and their interaction with other types of crystal defects (e.g., vacancies, interstitials, SFTs, and dislocation loops) $[35,57,87]$. These studies are informative as long as CTB lengths are limited to $10 \mathrm{~nm}$ order. However, the much longer CTBs usually observed in experiments are inherently defective with kink-like steps, which consist of segments of $\Sigma 3\{112\}$ incoherent twin boundaries (ITBs) and partial dislocations [88-90]. Moreover, the initial radiation cascades near a GB can change the local boundary structure since self-interstitial atoms resulting from the radiation can be easily absorbed by the nearby boundaries $[4,48,51]$. Therefore, it is expected that the perfect CTB structure may be changed by radiation-induced SIAs. The frequent distortion of CTBs observed in the irradiated nanotwinned Ag may confirm this hypothesis [81]. The structural changes of CTB may change its ability to absorb irradiated structural defects and improve its self-healing ability. Based on their experimental results, Li et al. [81] proposed a mechanism of the distortion and self-healing of CTBs, as illustrated in Figure 8. A small interstitial loop was generated by radiation near a CTB (a1). As the interstitial loop grows, its stress field may be large enough to deform the adjacent CTB (a2), forcing it to bend rightwards. Meanwhile, the atoms at CTBs rearrange themselves to accommodate the shape variation. The absorption of the interstitial loop by the CTB creates an interstitial-rich puddle locally (a3). The newly captured interstitials on the CTB could be highly mobile. The formation of two SFTs near the CTB prompts the interstitials to rapidly redistribute themselves along with the CTB into two smaller puddles right next to each SFT (b1). The annihilation of interstitials with SFTs leads to the gradual self-healing of the CTB (b2, b3). Figure 8 logically presents a radiation resistance mechanism of CTB based on 
the segregation of self-interstitial atoms, but direct evidence of self-healing processes at the atomic scale needs to be provided by atomistic simulation.

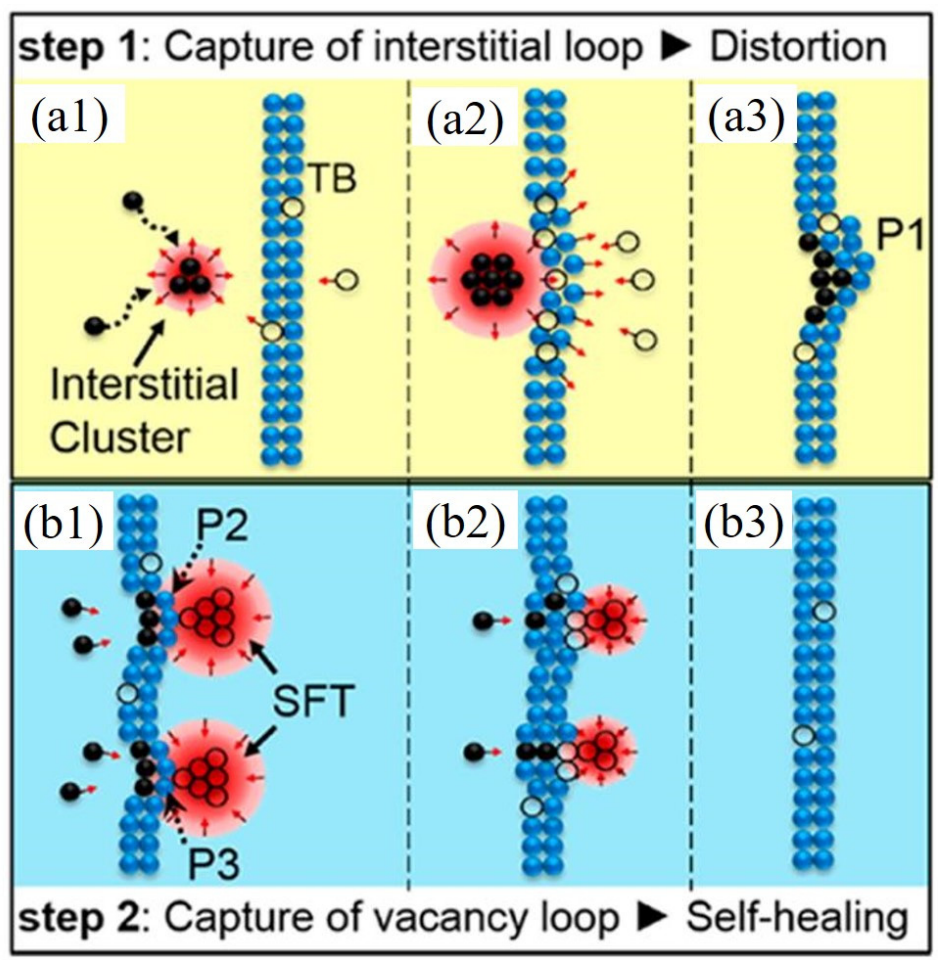

Figure 8. Schematics of the distortion and self-healing of a coherent twin boundary (CTB). (a1-a3) twin boundary captures interstitial atoms and becomes distortion. (b1-b3) twin boundary captures vacancies and becomes self-healing. Reproduced with permission from Ref. [81]. Copyright 2015 American Chemical Society.

As discussed above, the generally assumed perfect CTBs may usually have imperfect structures in real materials. To shed light on the unusual radiation resistance mechanism of nanotwinned metals, Zhang et al. [91] studied the dynamic interaction between twin boundaries and some typical radiation-induced structural defects by long-term MD simulations. Differently from the previous simulation models, which generally assume perfect CTBs to study their mechanical and physical properties, they considered the defective CTB structures containing either incoherent twin boundary (ITB) segment or interstitial atom clusters, which can better represent the real structure of CTB in materials, as shown in Figure 9 a,c. Based on the simulations, two possible self-healing mechanisms of nanotwinned metals to absorb the radiation-induced point defects are proposed. In the first simulation case, while a perfect CTB is ineffective for absorbing SFTs, a defective CTB structure containing ITB segments can provide a preferential site and diffusion channel to remove them. The absorption process of the point defects can be accelerated by the migration of ITB, as shown in Figure 9b. The second simulation case indicates that CTBs absorb SIAs preferentially over vacancies, and the SIAs exist on CTBs in the form of dislocation loop-like interstitial atom clusters. The SIA clusters on CTBs can subsequently provide absorption sites that favor the annihilation of vacancy clusters inside grains, as shown in Figure $9 \mathrm{~d}$. This self-healing mechanism of the twin interface is very similar to the process that is illustrated in Figure 8. Atomistic simulations have clearly shown that the defective structure of CTB is closely related to the ability to act as a sink for radiation-induced defects. The simulation results give a good explanation for the recent experimental results and provide further support for the design of radiation-tolerant nanotwinned materials. 


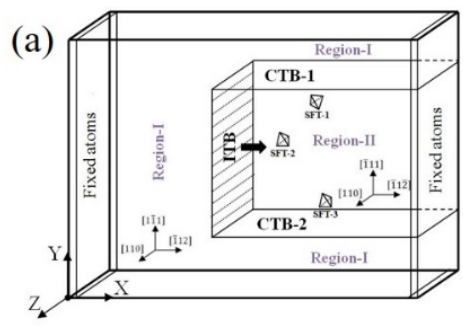

(b)
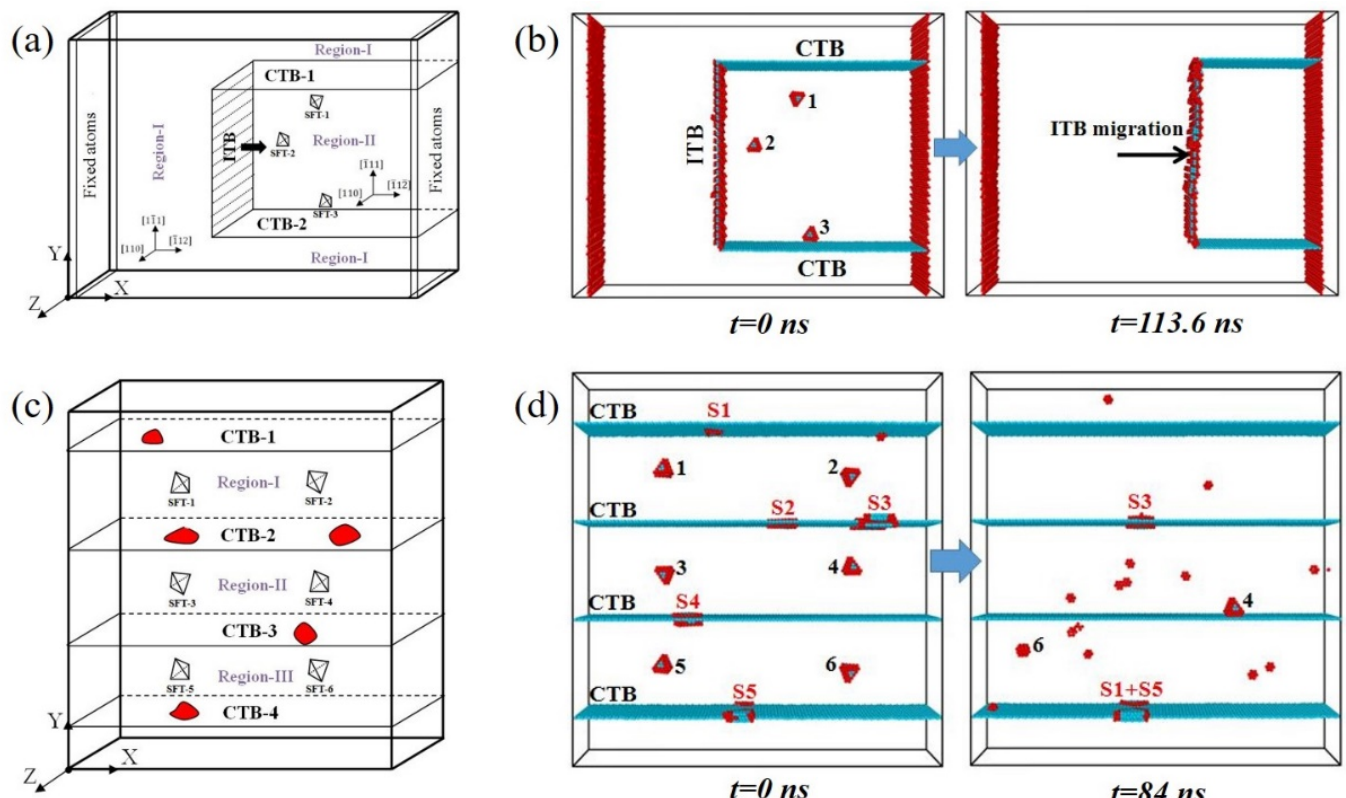

(d)

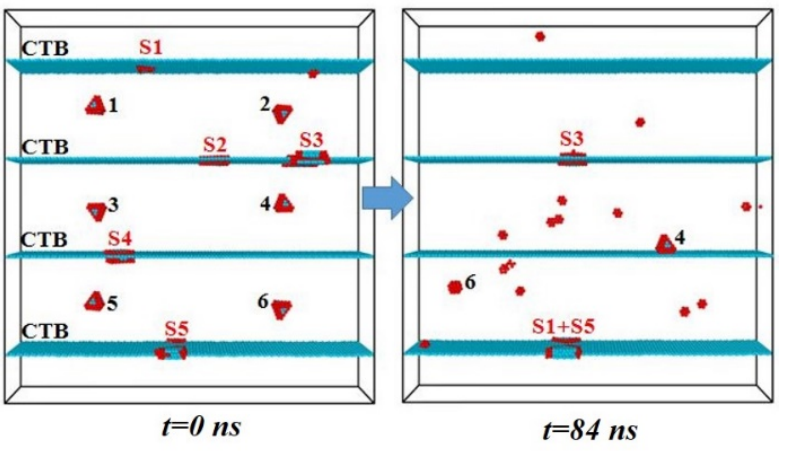

Figure 9. (a) Schematic of self-healing mechanism, based on incoherent twin boundary (ITB). (b) Interaction between migrating ITB and SFTs. (c) Schematic of self-healing mechanism, based on interstitial atoms segregation. (d) Interaction between SFTs and defective CTBs with interstitial atom clusters. Atoms are color coded according to their structures (cyan-HCP; red-other structure; FCC atoms not shown). Reproduced with permission from Ref. [91]. Copyright 2021 Clearance Center.

\section{Summary and Outlook}

Radiation damage of metals has long been a hot topic in the field of materials. Nanocrystalline metals have attracted extensive attention from material scientists because of their excellent radiation resistance. Progress has been made in the research of the radiation resistance mechanism of nanocrystalline metals in recent years. In this review article, the studies of radiation resistance and the self-healing mechanism of nanocrystalline metals by computational simulation is introduced. Simulations of interaction between GBs and collision cascades reveal that GBs exhibiting a biased absorption capacity of the interstitial atoms over vacancies. The sink ability of GBs for interacting with point defects is not only influenced by the intrinsic properties of GBs (e.g., GB structure and GB energy) but also depends on the radiation conditions through the absorbed defect content at the boundary. Simulations of dynamic interaction between GBs and structural defects reveal that GB migration is an important self-healing mechanism of materials under radiation, which accelerates the dissolution of the radiation-induced point defects and their clusters. Simulations of interaction between twin boundary and some typical radiation-induced point clusters (such as SFT and void) explained why nanotwinned metals can also exhibit unprecedented radiation tolerance, indicating that the defective structure of CTB plays an important role in the alleviation of radiation damage of the nanotwinned metals. The results of MD simulations provide atomistic perspectives and fundamental understandings for the design of radiation-resistant nanomaterials. However, there are still many scientific problems to be solved by future research.

Simulation results provide useful insight into how GBs influence radiation damage evolution, but most of the previous studies focused on the simple symmetric GB structures, which is far from the complex morphology of GB structure in real materials. More GBs with general structural characteristics should be used as research objects to explore new regularities in future modelling and simulation work. In addition, besides GBs, there are other sinks in any given material that will also influence radiation damage production. Surfaces, interfaces, and dislocations can all play similar roles. The study of these defect sinks is also important for advancing the understanding of the radiation resistance mecha- 
nism of nanomaterials. In situ experiments and combined computational simulations are effective research methods.

The excellent radiation resistance of nanocrystalline metals is due to their smaller grain size and larger GB volume fraction. However, an important characteristic of nanomaterials is poor structural stability and easy to grain growth, especially under the condition of temperature rise. Most of the radiation environment will encounter medium-high temperatures, so questions of how to keep the structural stability of nanocrystalline metals in the radiation environment and continue its excellent anti-radiation performance, remains to be further studied. For example, GB segregation of alloying elements is one of the strategies for improving the structural stability of nanomaterials. The computational simulation method can provide abundant information for this research plan.

The high strength and good tensile toughness of nanotwinned metal make it one of the promising candidate materials for future engineering application. Also, recent experimental and computational simulations show that twin boundaries with specific structures also have the ability of self-healing from radiation damage. Therefore, the computational simulation-aided microstructure design is expected to realize the simultaneous improvement of mechanical properties and radiation resistance ability of nanotwinned metals. Moreover, materials scientists have successfully explored a variety of methods for the synthesis of bulk nanocrystalline metals in the past decades. The above research provides an opportunity for the design and preparation of nanocrystalline metals with excellent comprehensive properties and the realization of nuclear industry application.

Funding: This research was supported by the National Key Research and Development Program of China (2020YFA0405900), the National Natural Science Foundation of China (52071034; 52130107), and the and the research grants from Japan Society for the Promotion of Science (P17711; 19H02415).

Data Availability Statement: Not available.

Conflicts of Interest: The author declares no conflict of interest.

\section{References}

1. Zhang, X.; Hattar, K.; Chen, Y.; Shao, L.; Li, J.; Sun, C.; Yu, K.; Li, N.; Taheri, M.L.; Wang, H.; et al. Radiation damage in nanostructured materials. Prog. Mater. Sci. 2018, 96, 217-321. [CrossRef]

2. Grimes, R.W.; Konings, R.J.M.; Edwards, L. Greater tolerance for nuclear materials. Nat. Mater. 2008, 7, 683-685. [CrossRef] [PubMed]

3. Ackland, G. Controlling Radiation Damage. Science 2010, 327, 1587-1588. [CrossRef]

4. Bai, X.M.; Voter, A.F.; Hoagland, R.G.; Nastasi, M.; Uberuaga, B.P. Efficient annealing of radiation damage near grain boundaries via interstitial emission. Science 2010, 327, 1631-1634. [CrossRef] [PubMed]

5. Kuksenko, V.; Pareige, C.; Pareige, P. Intra granular precipitation and grain boundary segregation under neutron irradiation in a low purity Fe-Cr based alloy. J. Nucl. Mater. 2012, 425, 125-129. [CrossRef]

6. Yu, K.Y.; Bufford, D.; Sun, C.; Liu, Y.; Wang, H.; Kirk, M.A.; Li, M.; Zhang, X. Removal of stacking-fault tetrahedra by twin boundaries in nanotwinned metals. Nat. Commun. 2013,4, 1377. [CrossRef]

7. Zhang, L.; Lu, C.; Tieu, K.; Su, L.; Zhao, X.; Pei, L. Stacking fault tetrahedron induced plasticity in copper single crystal. Mater. Sci. Eng. A 2017, 680, 27-38. [CrossRef]

8. Zhang, L.; Lu, C.; Pei, L.; Zhao, X.; Zhang, J.; Tieu, K. Evaluation of Mechanical Properties of $\Sigma 5(210) /[001]$ Tilt Grain Boundary with Self-Interstitial Atoms by Molecular Dynamics Simulation. J. Nanomater. 2017, 2017, 11. [CrossRef]

9. Bacon, D.J.; Gao, F.; Osetsky, Y.N. The primary damage state in fcc, bcc and hcp metals as seen in molecular dynamics simulations. J. Nucl. Mater. 2000, 276, 1-12. [CrossRef]

10. Wirth, B.D. How does radiation damage materials? Science 2007, 318, 923-924. [CrossRef] [PubMed]

11. Griffiths, M. A review of microstructure evolution in zirconium alloys during irradiation. J. Nucl. Mater. 1988, 159, 190-218. [CrossRef]

12. Ukai, S.; Fujiwara, M. Perspective of ODS alloys application in nuclear environments. J. Nucl. Mater. 2002, 307-311, 749-757. [CrossRef]

13. El-Genk, M.S.; Tournier, J.-M. A review of refractory metal alloys and mechanically alloyed-oxide dispersion strengthened steels for space nuclear power systems. J. Nucl. Mater. 2005, 340, 93-112. [CrossRef]

14. Alinger, M.J.; Odette, G.R.; Hoelzer, D.T. On the role of alloy composition and processing parameters in nanocluster formation and dispersion strengthening in nanostuctured ferritic alloys. Acta Mater. 2009, 57, 392-406. [CrossRef] 
15. Hsiung, L.L.; Fluss, M.J.; Tumey, S.J.; Choi, B.W.; Serruys, Y.; Willaime, F.; Kimura, A. Formation mechanism and the role of nanoparticles in Fe-Cr ODS steels developed for radiation tolerance. Phys. Rev. B 2010, 82, 184103. [CrossRef]

16. Kirk, M.; Yi, X.; Jenkins, M. Characterization of irradiation defect structures and densities by transmission electron microscopy. J. Mater. Res. 2015, 30, 1195-1201. [CrossRef]

17. Zhang, X.; Fu, E.G.; Misra, A.; Demkowicz, M.J. Interface-enabled defect reduction in He ion irradiated metallic multi-layers. JOM 2010, 62, 75-78. [CrossRef]

18. Demkowicz, M.J.; Misra, A.; Caro, A. The role of interface structure in controlling high helium concentrations. Curr. Opin. Solid State Mater. Sci. 2012, 16, 101-108. [CrossRef]

19. Heinisch, H.L.; Gao, F.; Kurtz, R.J. The effects of interfaces on radiation damage production in layered metal composites. J. Nucl. Mater. 2004, 329-333, 924-928. [CrossRef]

20. Wang, J.; Kang, K.; Zhang, R.F.; Zheng, S.J.; Beyerlein, I.J.; Mara, N.A. Structure and Property of Interfaces in ARB Cu/Nb Laminated Composites. JOM 2012, 64, 1208-1217. [CrossRef]

21. Farrell, K.; Maziasz, P.J.; Lee, E.H.; Mansur, L.K. Modification of radiation damage microstructure by helium. Radiat. Eff. 1983, 78, 277-295. [CrossRef]

22. Zinkle, S.J.; Farrell, K. Void swelling and defect cluster formation in reactor-irradiated copper. J. Nucl. Mater. 1989, 168, $262-267$. [CrossRef]

23. Thorsen, P.A.; Bilde-Sørensen, J.B.; Singh, B.N. Bubble formation at grain boundaries in helium implanted copper. Scr. Mater. 2004, 51, 557-560. [CrossRef]

24. Matsukawa, Y.; Zinkle, S.J. One-Dimensional Fast Migration of Vacancy Clusters in Metals. Science 2007, 318, 959-962. [CrossRef] [PubMed]

25. Beyerlein, I.J.; Caro, A.; Demkowicz, M.J.; Mara, N.A.; Misra, A.; Uberuaga, B.P. Radiation damage tolerant nanomaterials. Mater Today 2013, 16, 443-449. [CrossRef]

26. Plimpton, S. Fast Parallel Algorithms for Short-Range Molecular Dynamics. J. Comput. Phys. 1995, 117, 1-19. [CrossRef]

27. Li, J. AtomEye: An efficient atomistic configuration viewer. Model. Simul. Mater. Sci. Eng. 2003, 11, 173-177. [CrossRef]

28. Stukowski, A. Visualization and analysis of atomistic simulation data with OVITO-the Open Visualization Tool. Model. Simul. Mater. Sci. Eng. 2010, 18, 015012. [CrossRef]

29. Stukowski, A. Structure identification methods for atomistic simulations of crystalline materials. Model. Simul. Mater. Sci. Eng. 2012, 20, 045021. [CrossRef]

30. Stukowski, A.; Albe, K. Dislocation detection algorithm for atomistic simulations. Model. Simul. Mater. Sci. Eng. 2010, 18, 025016. [CrossRef]

31. Samaras, M.; Derlet, P.M.; van Swygenhoven, H.; Victoria, M. Computer Simulation of Displacement Cascades in Nanocrystalline Ni. Phys. Rev. Lett. 2002, 88, 125505. [CrossRef]

32. Samaras, M.; Derlet, P.M.; van Swygenhoven, H.; Victoria, M. Radiation damage near grain boundaries. Philos. Mag. 2003, 83, 3599-3607. [CrossRef]

33. Samaras, M.; Derlet, P.M.; van Swygenhoven, H.; Victoria, M. Stacking fault tetrahedra formation in the neighbourhood of grain boundaries. Nucl. Instrum. Methods Phys. Res. Sect. B 2003, 202, 51-55. [CrossRef]

34. Samaras, M.; Derlet, P.M.; Swygenhoven, H.V.; Victoria, M. Atomic scale modelling of the primary damage state of irra-diated fcc and bcc nanocrystalline metals. J. Nucl. Mater. 2006, 351, 47-55. [CrossRef]

35. Demkowicz, M.J.; Anderoglu, O.; Zhang, X.; Misra, A. The influence of $\sum 3$ twin boundaries on the formation of radia-tion-induced defect clusters in nanotwinned Cu. J. Mater. Res. 2011, 26, 1666-1675. [CrossRef]

36. Bai, X.-M.; Vernon, L.J.; Hoagland, R.G.; Voter, A.F.; Nastasi, M.; Uberuaga, B.P. Role of atomic structure on grain bound-ary-defect interactions in Cu. Phys. Rev. B 2012, 85, 214103. [CrossRef]

37. Bai, X.-M.; Uberuaga, B.P. Multi-timescale investigation of radiation damage near TiO2 rutile grain boundaries. Philos. Mag. 2012, 92, 1469-1498. [CrossRef]

38. Pérez, F.J.P.; Smith, R. Modelling radiation effects at grain boundaries in bcc iron. Nucl. Instrum. Methods Phys. Res. Sect. B 1999, 153, 136-141. [CrossRef]

39. Pérez-Pérez, F.J.; Smith, R. Structural changes at grain boundaries in bcc iron induced by atomic collisions. Nucl. Instrum. Methods Phys. Res. Sect. B 2000, 164-165, 487-494. [CrossRef]

40. Pérez-Pérez, F.J.; Smith, R. Preferential damage at symmetrical tilt grain boundaries in bcc iron. Nucl. Instrum. Methods Phys. Res. Sect. B 2001, 180, 322-328. [CrossRef]

41. Van Brutzel, L.; Vincent-Aublant, E. Grain boundary influence on displacement cascades in UO2: A molecular dynamics study. J. Nucl. Mater. 2008, 377, 522-527. [CrossRef]

42. van Brutzel, L.; Vincent-Aublant, E.; Delaye, J.M. Large molecular dynamics simulations of collision cascades in sin-gle-crystal, bi-crystal, and poly-crystal UO2. Nucl. Instrum. Methods Phys. Res. Sect. B 2009, 267, 3013-3016. [CrossRef]

43. Moriani, A.; Cleri, F. Point-defect recombination efficiency at grain boundaries in irradiated SiC. Phys. Rev. B 2006, 73, 214113. [CrossRef]

44. Gao, F.; Chen, D.; Hu, W.; Weber, W.J. Energy dissipation and defect generation in nanocrystalline silicon carbide. Phys. Rev. B 2010, 81, 184101. [CrossRef] 
45. Swaminathan, N.; Kamenski, P.J.; Morgan, D.; Szlufarska, I. Effects of grain size and grain boundaries on defect produc-tion in nanocrystalline 3C-SiC. Acta Mater. 2010, 58, 2843-2853. [CrossRef]

46. Swaminathan, N.; Wojdyr, M.; Morgan, D.D.; Szlufarska, I. Radiation interaction with tilt grain boundaries in $\beta$-SiC. J. Appl. Phys. 2012, 111, 054918. [CrossRef]

47. Sugio, K.; Shimomura, Y.; Rubia, T.D.d. Computer Simulation of Displacement Damage Cascade Formation near Sigma 5 Twist Boundary in Silver. J. Phys. Soc. Jpn. 1998, 67, 882-889. [CrossRef]

48. Bai, X.M.; Uberuaga, B.P. The Influence of Grain Boundaries on Radiation-Induced Point Defect Production in Materials: A Review of Atomistic Studies. JOM 2013, 65, 360-373. [CrossRef]

49. Tschopp, M.A.; Solanki, K.N.; Gao, F.; Sun, X.; Khaleel, M.A.; Horstemeyer, M.F. Probing grain boundary sink strength at the nanoscale: Energetics and length scales of vacancy and interstitial absorption by grain boundaries in $\alpha$-Fe. Phys. Rev. B 2012, 85, 064108. [CrossRef]

50. Li, X.; Liu, W.; Xu, Y.; Liu, C.S.; Pan, B.C.; Liang, Y.; Fang, Q.F.; Chen, J.L.; Luo, G.N.; Lu, G.H.; et al. Radiation resistance of nano-crystalline iron: Coupling of the fundamental segregation process and the annihilation of interstitials and vacancies near the grain boundaries. Acta Mater. 2016, 109, 115-127. [CrossRef]

51. Martinez, E.; Uberuaga, B.P. Mobility and coalescence of stacking fault tetrahedra in Cu. Sci. Rep. 2015, 5, 9084. [CrossRef]

52. Rose, M.; Balogh, A.G.; Hahn, H. Instability of irradiation induced defects in nanostructured materials. Nucl. Instrum. Methods Phys. Res. Sect. B 1997, 127-128, 119-122. [CrossRef]

53. Chimi, Y.; Iwase, A.; Ishikawa, N.; Kobiyama, M.; Inami, T.; Okuda, S. Accumulation and recovery of defects in ion-irradiated nanocrystalline gold. J. Nucl. Mater. 2001, 297, 355-357. [CrossRef]

54. Shen, T.D.; Feng, S.; Tang, M.; Valdez, J.A.; Wang, Y.; Sickafus, K.E. Enhanced radiation tolerance in nanocrystalline $\mathrm{MgGa}_{2} \mathrm{O}_{4}$. Appl. Phys. Lett. 2007, 90, 263115. [CrossRef]

55. Beyerlein, I.J.; Demkowicz, M.J.; Misra, A.; Uberuaga, B.P. Defect-interface interactions. Prog. Mater. Sci. 2015, 74, 125-210. [CrossRef]

56. Borovikov, V.; Tang, X.Z.; Perez, D.; Bai, X.M.; Uberuaga, B.P.; Voter, A.F. Coupled motion of grain boundaries in bcc tungsten as a possible radiation-damage healing mechanism under fusion reactor conditions. Nucl. Fusion 2013, 53, 063001. [CrossRef]

57. Martínez, E.; Uberuaga, B.P.; Beyerlein, I.J. Interaction of small mobile stacking fault tetrahedra with free surfaces, dislo-cations, and interfaces in $\mathrm{Cu}$ and $\mathrm{Cu}-\mathrm{Nb}$. Phys. Rev. B 2016, 93, 054105. [CrossRef]

58. Mansur, L.K. Theory and experimental background on dimensional changes in irradiated alloys. J. Nucl. Mater. 1994, 216, 97-123. [CrossRef]

59. Abe, H.; Sekimura, N.; Tadokoro, T.J.M.T. Stability and mobility of interstitial-type defect clusters generated from displacement cascades in copper and gold by in-situ transmission electron microscopy. Mater. Trans. 2005, 46, 433-439. [CrossRef]

60. Merkle, K.L.; Thompson, L.J.; Phillipp, F. In-Situ HREM Studies of Grain Boundary Migration. Interface Sci. 2004, 12, 277-292. [CrossRef]

61. Molodov, K.D.; Molodov, D.A. Grain boundary mediated plasticity: On the evaluation of grain boundary migration-Shear coupling. Acta Mater. 2018, 153, 336-353. [CrossRef]

62. Rupert, T.J.; Gianola, D.S.; Gan, Y.; Hemker, K.J. Experimental observations of stress-driven grain boundary migration. Science 2009, 326, 1686-1690. [CrossRef]

63. Farkas, D.; Frøseth, A.; van Swygenhoven, H. Grain boundary migration during room temperature deformation of nanocrystalline Ni. Scr. Mater. 2006, 55, 695-698. [CrossRef]

64. Zhang, L.; Lu, C.; Shibuta, Y. Shear response of grain boundaries with metastable structures by molecular dynamics sim-ulations. Model. Simul. Mater. Sci. Eng. 2018, 26, 035008. [CrossRef]

65. Zhang, L.; Lu, C.; Michal, G.; Tieu, K.; Zhao, X.; Deng, G. Influence of temperature and local structure on the shear-coupled grain boundary migration. Phys. Status Solidi B 2017, 254, 1600477. [CrossRef]

66. Jin, M.; Cao, P.; Yip, S.; Short, M.P. Radiation damage reduction by grain-boundary biased defect migration in nanocrystalline Cu. Acta Mater. 2018, 155, 410-417. [CrossRef]

67. Molodov, D.A.; Gorkaya, T.; Gottstein, G. Mechanically driven migration of $<100>$ tilt grain boundaries in Al-Bicrystals. In Materials Science Forum; Trans Tech Publications Ltd.: Stafa-Zurich, Switzerland, 2007; pp. 927-932.

68. Mompiou, F.; Caillard, D.; Legros, M. Grain boundary shear-migration coupling-I. In situ TEM straining experiments in Al polycrystals. Acta Mater. 2009, 57, 2198-2209. [CrossRef]

69. Yu, K.Y.; Bufford, D.; Khatkhatay, F.; Wang, H.; Kirk, M.A.; Zhang, X. In situ studies of irradiation-induced twin boundary migration in nanotwinned Ag. Scr. Mater. 2013, 69, 385-388. [CrossRef]

70. Cahn, J.W.; Mishin, Y.; Suzuki, A. Coupling grain boundary motion to shear deformation. Acta Mater. 2006, 54, 4953-4975. [CrossRef]

71. Zhang, H.; Du, D.; Srolovitz, D.J. Effects of boundary inclination and boundary type on shear-driven grain boundary migration. Philos. Mag. 2008, 88, 243-256. [CrossRef]

72. Zhang, H.; Srolovitz, D.J.; Douglas, J.F.; Warren, J.A. Atomic motion during the migration of general [0 01 1] tilt grain boundaries in Ni. Acta Mater. 2007, 55, 4527-4533. [CrossRef]

73. Zhang, L.; Lu, C.; Tieu, K.; Shibuta, Y. Dynamic interaction between grain boundary and stacking fault tetrahedron. Scr. Mater. 2018, 144, 78-83. [CrossRef] 
74. Zhang, L.; Shibuta, Y.; Lu, C.; Huang, X. Interaction between nano-voids and migrating grain boundary by molecular dynamics simulation. Acta Mater. 2019, 173, 206-224. [CrossRef]

75. Lu, L.; Shen, Y.; Chen, X.; Qian, L.; Lu, K. Ultrahigh Strength and High Electrical Conductivity in Copper. Science 2004, 304, 422-426. [CrossRef] [PubMed]

76. Lu, L.; Chen, X.; Huang, X.; Lu, K. Revealing the maximum strength in nanotwinned copper. Science 2009, 323, 607-610. [CrossRef]

77. Zhang, X.; Misra, A.; Wang, H.; Nastasi, M.; Embury, J.D.; Mitchell, T.E.; Hoagland, R.G.; Hirth, J.P. Na-noscale-twirming-induced strengthening in austenitic stainless steel thin films. Appl. Phys. Lett. 2004, 84, 1096-1098. [CrossRef]

78. Han, W.Z.; Demkowicz, M.J.; Fu, E.G.; Wang, Y.Q.; Misra, A. Effect of grain boundary character on sink efficiency. Acta Mater. 2012, 60, 6341-6351. [CrossRef]

79. Chen, Y.; Li, J.; Yu, K.Y.; Wang, H.; Kirk, M.A.; Li, M.; Zhang, X. In situ studies on radiation tolerance of nanotwinned Cu. Acta Mater. 2016, 111, 148-156. [CrossRef]

80. Chen, Y.; Yu, K.Y.; Liu, Y.; Shao, S.; Wang, H.; Kirk, M.A.; Wang, J.; Zhang, X. Damage-tolerant nanotwinned metals with nanovoids under radiation environments. Nat. Commun. 2015, 6, 7036. [CrossRef]

81. Li, J.; Yu, K.Y.; Chen, Y.; Song, M.; Wang, H.; Kirk, M.A.; Li, M.; Zhang, X. In Situ Study of Defect Migration Kinetics and Self-Healing of Twin Boundaries in Heavy Ion Irradiated Nanotwinned Metals. Nano Lett. 2015, 15, 2922-2927. [CrossRef] [PubMed]

82. Jiao, S.; Kulkarni, Y. Radiation tolerance of nanotwinned metals-An atomistic perspective. Comput. Mater. Sci. 2018, 142, 290-296. [CrossRef]

83. Wu, L.; Yu, W.; Hu, S.; Shen, S. Radiation response of nanotwinned Cu under multiple-collision cascades. J. Nucl. Mater. 2018, 505, 183-192. [CrossRef]

84. Pei, L.; Lu, C.; Zhao, X.; Zhang, L.; Cheng, K.; Michal, G.; Tieu, K. Brittle versus ductile behaviour of nanotwinned copper: A molecular dynamics study. Acta Mater. 2015, 89, 1-13. [CrossRef]

85. Zhao, X.; Lu, C.; Tieu, A.K.; Pei, L.; Zhang, L.; Cheng, K.; Huang, M. Strengthening mechanisms and dislocation processes in $<111>$ textured nanotwinned copper. Mater. Sci. Eng. A 2016, 676, 474-486. [CrossRef]

86. Zhao, X.; Lu, C.; Tieu, A.K.; Pei, L.Q.; Zhang, L.; Su, L.H.; Zhan, L.H. Deformation mechanisms in nanotwinned copper by molecular dynamics simulation. Mater. Sci. Eng. A 2017, 687, 343-351. [CrossRef]

87. Jin, Z.H.; Gumbsch, P.; Albe, K.; Ma, E.; Lu, K.; Gleiter, H.; Hahn, H. Interactions between non-screw lattice dislocations and coherent twin boundaries in face-centered cubic metals. Acta Mater. 2008, 56, 1126-1135. [CrossRef]

88. Wang, Y.M.; Sansoz, F.; LaGrange, T.; Ott, R.T.; Marian, J.; Barbee, T.W.; Hamza, A.V. Defective twin boundaries in nanotwinned metals. Nat. Mater. 2013, 12, 697-702. [CrossRef] [PubMed]

89. Greer, J.R. Nanotwinned metals: It's all about imperfections. Nat. Mater. 2013, 12, 689-690. [CrossRef] [PubMed]

90. Xu, L.; Xu, D.; Tu, K.N.; Cai, Y.; Wang, N.; Dixit, P.; Pang, J.H.L.; Miao, J.M. Structure and migration of (112) step on (111) twin boundaries in nanocrystalline copper. J. Appl. Phys. 2008, 104, 113717. [CrossRef]

91. Zhang, L.; Shibuta, Y.; Lu, C.; Huang, X. Atomistic Simulation of the Interaction Between Point Defects and Twin Boundary. Phys. Status Solidi B 2018, 255, 1800228. [CrossRef] 